\title{
PORTADORES DE NECESSIDADES ESPECIAIS: 0 CASO DO INSTITUTO DE EDUCAÇÃO E REABILITAÇÃO DOS CEGOS DO RIO GRANDE DO NORTE
}

\author{
Alessandra Patrícia de Araújo \\ Edineide da Silva Marques \\ Maria Luzia Alexandre de Oliveira \\ Eliane Ferreira da Silva
}

\section{Resumo:}

Contempla o início de estudos que visam refletir sobre a inclusão de pessoas com necessidades especiais visuais na sociedade globalizada, ao considerar que o acesso à informação tornou-se um diferencial frente às novas tecnologias que aceleram a sua utilização. Assim, esta pesquisa analisa a integração desse indivíduo. Utiliza-se da metodologia bibliográfica, bem como da pesquisa de campo através da observação baseada em evidências, resultado de entrevistas e visitas a instituição especializada. Verificar-se, também a importância da inclusão social e enfatiza a necessidade do profissional da informação nesse processo. Concluiu-se que o bibliotecário é fundamental em uma unidade de informação, seja ela especial ou não. Contudo, sua capacitação é imprescindível para o processo de tomada de decisões aliada ao trabalho conjunto com os governos (municipal, estadual e/ou federal) também pode abranger as Organizações Não Governamentais (ONGs).

\section{Palavras-Chave:}

Biblioteca - inclusão; Portadores de necessidades especiais visuais; Atuação do profissional da informação

\section{VISUAL IMPAIRMENT PEOPLE: THE CASE OF "RIO GRANDE DO NORTE EDUCATION AND REHABILITATION INSTITUTE OF BLINDS"}

\begin{abstract}
:
Contemplates the beginning of studies, which aim at reflecting upon the inclusion of people with visual impairment into the globalized society, taking into account that the access to information has become a differential towards the new technology that speed its use. Thus, this research analyzes the integration of this individual. Utilizes the bibliographical methodology, as well as researches based on observations of evidences, interview results and several visits to specialized institutions. The importance of social inclusion is also verified, and the need of participation of the information professional in this process is emphasized. Comes to the conclusion that the librarian is fundamental in an information unit, wether it is aimed to special needs or not. However, the training of professionals is extremely necessary when it comes to the decision making process joined with operations with the Government and NGOs (Non-governmental organizations).
\end{abstract}

\section{Keywords:}

Library - inclusion.; Visual impairment; Information professional’s role 


\section{INTRODUÇÃO}

Falar sobre deficiência não é tão simples, uma vez que cada indivíduo atribui uma concepção diferente acerca dessa problemática. Ultimamente, esse tema tem se tornado foco de inúmeros estudos. Com efeito, essa é uma questão que envolve toda a sociedade, nos seus mais variados segmentos: políticos, sociais e/ou educacionais.

Nessa perspectiva, o presente estudo teve como finalidade destacar a integração de pessoas com deficiência visual em Unidades de Informação, mais precisamente, o Instituto de Educação e Reabilitação dos Cegos do Rio Grande do Norte (IERC/RN). Esta pesquisa tornou-se oportuna, pelo Instituto já desenvolver uma sistemática de integração do deficiente e por ser o único do Estado do RN a realizar esse trabalho de integração social. Por isso, ele torna-se o ponto focal da sociedade norte-riograndense para considerações desse âmbito. Além disso, escolheu-se essa instituição pelo fato da grande procura dos deficientes visuais a mesma. Por isso, trabalhos como este são relevantes à medida que o desenvolvimento desta pesquisa pode contribuir para melhorias do serviço em uma perspectiva sistêmica da qualidade. Os seus resultados podem despertar o interesse para a importância dos desdobramentos positivos da integração de tais indivíduos no exercício de sua cidadania.

Utilizou-se como metodologia a pesquisa bibliográfica, a qual, de acordo com Ferreira (1986, p. 20), constitui-se, na "análise e estudo dos textos impressos, com vista à elaboração de repertórios gerais ou especializados, e que compreende as fases de pesquisa, transcrição, descrição e classificação”. Também se insere na classificação como pesquisa de campo, devido ao pesquisador estar presente durante a coleta dos dados, isto é, o pesquisador necessita deslocar-se do seu ambiente acadêmico, visualizando a aquisição de respostas para o problema de pesquisa. (GIL, 2002).

Além disso, foi usada, também, como técnica de coleta dos dados a entrevista e tornou-se mais adequada para o desenvolvimento de levantamentos sociais (GIL, 2002). Tal entrevista formulou-se a partir de conversas com profissionais relacionados à Instituição e visitas para a observação da mesma. Esses procedimentos possibilitaram as pesquisadoras terem uma visão holística da Instituição e dos serviços oferecidos.

(c) Revista Digital de Biblioteconomia e Ciência da Informação,Campinas, v.5, n. 2, p. 67-86, jan/jun. 2008- ISSN: 1678-765X. 
A pesquisa encontra-se estruturada da seguinte maneira: inicia-se descrevendo como o deficiente era visto pela sociedade na antiguidade até os dias atuais. Destaca-se o conceito de pessoas portadoras de deficiência. Em seguinte, traz-se um enfoque sobre o deficiente visual. Contextualiza seus direitos e deveres, através de legislações. Destaca as dificuldades provenientes das questões relacionadas à locomoção, ao uso do Sistema Braille e das novas tecnologias.

Na continuação, aborda-se sobre o IERC/RN, passando para o enfoque das atividades desenvolvidas com vistas à integração do deficiente visual na sociedade. Aliado a isso, foram feitas algumas considerações sobre a importância do profissional da informação bibliotecário para essa inclusão social. Por fim, teceram-se algumas considerações finais sobre a pesquisa, destacando os pontos mais importantes abordados, seguidos das referências utilizadas em sua elaboração.

\section{BREVE HISTÓRICO SOBRE DEFICIÊNCIA}

Ao falar sobre deficiência torna-se importante fazer um resgate histórico para melhor expor os fatos. Já que essas circunstâncias mostram em síntese às lutas, às conquistas, às relações entre as comunidades no decorrer dos tempos. E a idéia que se fazia do sujeito deficiente na sociedade? E como este se encontrava?

Revela-se que na antiguidade, as crianças com deficiência, seja ela qual fosse, eram percebidas pela sociedade com piedade e compaixão, como pessoas castigadas pelos deuses e enjeitadas. Por essas razões eram abandonadas e impossibilitadas da existência. Idéia essa, não só existia no meio da massa da sociedade, mas também permanece entre os estudiosos e pensadores da época como Platão e Aristóteles, que defendiam a eliminação das crianças com deficiência. Mais tarde, Martin Luther, já na Idade Média, seguia a mesma linha dos pensamentos e das ações cruéis. Afirma Beyer (2005, p. 14):

\footnotetext{
As cidades gregas de Atenas e Esparta havia uma lei que defendia como também fomentava o genocídio de crianças com deficiência - Martin Luther, o reformulador protestante, aconselhava que se matasse as assim denominadas 'crianças monstras'. Educação e deficiência, criança com deficiência na escola, tal situação raramente se deu na história.
}

Vê-se, o preconceito que chegava ao maior grau da injustiça, da ignorância, da perversidade, enfim da frieza humana. 
Nas últimas décadas, a conquista por um espaço de igualdade segue um processo histórico de lutas e reivindicações por parte de grupos organizados. Essas pessoas tiveram de enfrentar até mesmo a classificação de diversos termos semânticos, que os ditos “normais” iam criando para classificá-los em um grupo de excluídos (paralítico, aleijado, excepcional, doente mental, anormal, doido, mongolóide... deficiente). Todas essas palavras têm relação com o profundo desconhecimento que a maioria das pessoas acumulam durante suas vidas, são reflexos das imagens que visualizam e incorporam como "pessoas capacitadas” de participarem ativamente na sociedade. (BUSCAGLIA, 1997).

A citada autora continua e explica que a terminologia pessoa portadora de deficiência tenta estabelecer a idéia de que a deficiência está no indivíduo, mas não, é o indivíduo deficiente. O verbo portar significa carregar, trazer. Mas como o sujeito pode carregar algo, se este algo não existe, se este é justamente uma ausência ou redução.

Entretanto, mesmo que atualmente a adoção do termo PPD (pessoa portadora de deficiência) seja questionada, e uma nova definição venha a substituí-la: Portadores de Necessidades Especiais - PNES, o mais importante é que haja uma discussão a fim de definir não só termos e conceitos mais coerentes. Sobretudo, fornecer à sociedade informações claras e contundentes, atenuando a discriminação, além de, primordialmente, esclarecer a própria PPD quanto aos seus direitos e proteção legal. (BRASIL, 1994).

A proteção as PPDs advém dos direitos comuns a todo cidadão, isto é, todos os direitos constitucionais e leis decorrem, comuns a todos. Essa proteção atua no campo do Município e/ou do Estado garantindo o estabelecimento das políticas correntes, tanto no campo da seguridade social, como também da educação, do trabalho e da justiça, fazendo valer à “força” da lei os seus direitos fundamentais. Para dar prosseguimento ao contexto, faz-se necessário esclarecer sobre os conceitos de deficiência visual, partindo de esclarecimentos sobre a cegueira e a visão subnormal ou parcial. 


\title{
3 DEFICIÊNCIA VISUAL
}

A lei $\mathrm{n}^{0}$ 7.583, de 24 de outubro de 1989, determina que pessoas portadoras de deficiência visual e parcial devem ser integradas à sociedade através do trabalho, para que possam exercer sua cidadania.

Segundo Brasil (1994, p. 13) indivíduos com deficiência visual são aqueles “cegos e com baixa visão (visão parcial ou visão subnormal)"; as primeiras não têm visão suficiente para aprender a ler em tinta e necessitam utilizar outros sentidos no processo de desenvolvimento e aprendizagem. As com baixa visão são aquelas que utilizam seu pequeno potencial visual para explorar o ambiente, conhecer o mundo e aprender a ler e escrever.

De acordo com Masini (1994, p. 83) tais deficientes são classificados a partir da “acuidade visual: sendo cego aquele que dispõe de 20/200 de visão no melhor olho, após correção". Por sua vez, portador de visão subnormal são os que dispõem de "20/70 de visão nas mesmas condições”. Enquanto o termo cegueira é conceituado da seguinte forma:

\begin{abstract}
Cegueira é a perda total e/ou resíduos mínimos de visão, que leva o indivíduo a necessitar do "Sistema Braille", como meio de leitura e escrita, além de outros equipamentos específicos para o desenvolvimento educação e integração social [...] visão subnormal trata-se da pessoa que possui resíduo visual que a possibilita ler impressos a tinta, de forma ampliada ou com o uso de equipamentos específicos. (TIBOLA [19-?] apud FERNANDES, 2000, p. 4)
\end{abstract}

Tanto o portador de cegueira total, como o de visão subnormal carecem de recursos didáticos especiais, para garantir suas possibilidades de desenvolvimento e participação na sociedade.

A deficiência visual pode tanto ser congênita quanto adquirida em diferentes épocas da vida; o que acarreta diferenças no processo cognitivo e na conseqüente estruturação das formas de relação para estes indivíduos. Assim, são classificados em quatro grupos: os cegos congênitos ou de cegueira adquirida até os cinco anos, os de cegueira adquirida depois dessa idade, os de visão subnormal congênita e os de visão subnormal adquirida. (MASINI, 1994). 
Diante disto, falar-se-á sobre as dificuldades de locomoção para o acesso as informações, explanando sobre as leis que asseguram seus direitos, destacando as barreiras encontradas pelo deficiente visual.

\subsection{DIFICULDADES DE LOCOMOÇÃO PARA ACESSO AS INFORMAÇÕES}

Segundo dados da Organização Mundial de Saúde (OMS) (2001 apud ESTABEL; MORO; SANTAROSA, 2006, p. 2) existem aproximadamente "40 milhões de pessoas com necessidades especiais com limitação visual no mundo, das quais $75 \%$ são provenientes de regiões de baixo poder socioeconômico”. No Brasil, tal incidência está na "faixa de $1 \%$ a $1,5 \%$ da população, sendo de uma entre 3 mil com cegueira, e de um entre 500 com baixa visão”.

A partir dessas observações estatísticas, verifica-se a necessidade de reflexões, para que a sociedade veja tal deficiência não como uma limitação, mas como uma troca de experiências, fazendo com que possa ser compartilhada, compreendida e haja interação na construção de uma sociedade mais igualitária.

No contexto inclusivo pode-se destacar a Constituição Federativa do Brasil de 1988, que sinalizava em seu artigo $5^{\circ}$ que todos somos iguais perante a lei, com o direito à vida, à igualdade, à segurança e à propriedade, através do livre exercício do trabalho; e esclarece ainda, que a lei punirá quaisquer discriminações atentatórias dos direitos e liberdades fundamentais. Além disso, a Constituição Federal de 1988 ressalta a proteção à pessoa com deficiência, tanto para a área de saúde (art. 23), como a empregabilidade (art. 37), para a educação e ensino (art. 208).

Assim, a inclusão faz parte do desenvolvimento de uma nação. O Brasil a partir dos anos 80 com o processo de democratização política, após o Regime Militar (1964-1985) viu surgir um novo caminho contra o entrave do preconceito. Associações de pessoas deficientes foram citadas nesta época, e tiveram papel de destaque nos movimentos que lutavam pela garantia dos seus direitos, inclusive no mercado de trabalho.

Quanto ao processo de locomoção, Pinheiro (2004) destaca algumas barreiras que os deficientes visuais encontram, são elas:

(c) Revista Digital de Biblioteconomia e Ciência da Informação,Campinas, v.5, n. 2, p. 67-86, jan/jun. 2008- ISSN: 1678-765X. 
- as arquitetônicas (escadas no ambiente, altas estantes e pouco espaço entre uma e outra para movimento, poucas rampas de acesso e falta de elevadores);

- dificuldades de comunicação e compreensão (o deficiente visual necessita de encaminhamento);

- falta de materiais especializados (a não disponibilização de métodos - Braille - devido ao seu alto custo, além de materiais como fitas de áudio, livros fonados e leitores);

- falta de capacidade profissional (colaboradores qualificados para atender o deficiente, conhecendo suas técnicas de comunicação, para assim ajudá-los em suas buscas).

No Brasil, existem legislações que procuram incluir a pessoa com deficiência na sociedade. Contudo, para este estudo será explorada aquela explicita para o deficiente visual. Assim, destaca-se o Decreto n ${ }^{0}$ 3298, de 20 de dezembro de 1999, que apresenta a acuidade visual, conforme expresso pela Tabela de Snellen ${ }^{1}$.

Para a acessibilidade, a Lei Federal $n^{0}$ 10.098, de 19 de dezembro de 2000, descreve providências para a urbanização e desenho do mobiliário urbano, possibilitando o acesso a edifícios, transporte coletivo, além dos sistemas de comunicação e sinalização, ajudando a diminuir a barreira existente entre os deficientes visuais.

O contexto dos transportes foi ampliado e melhor apresentado através da criação do Decreto Federal $\mathrm{n}^{\circ}$ 3.691, de 19 de dezembro de 2000, que dá acesso gratuito ao deficiente, isentando-o do pagamento das tarifas. Essa ação é o chamado passe livre. Mas, deve ser apresentada a carteira de deficiente visual.

Outro ponto de destaque para a inclusão do deficiente visual é através da educação, proporcionando a oferta de educação especial, que segundo a Lei Federal $n^{\circ}$ 9.394, de 20 de dezembro de 1996, que estabelece as Diretrizes e Bases da Educação Nacional, as escolas devem atender as peculiaridades da clientela, tendo seu início na faixa etária de 0 a 6 anos.

\footnotetext{
${ }^{1}$ Mede a habilidade do olho em perceber letras de alto contraste, mas não avalia adequadamente a habilidade de ver em padrões de baixo contraste.
}

(c) Revista Digital de Biblioteconomia e Ciência da Informação,Campinas, v.5, n. 2, p. 67-86, jan/jun. 2008- ISSN: 1678-765X. 
Ainda na conjuntura educacional, voltada para o deficiente visual, existe a Lei no 9.045, de 18 de maio de 1995, ao discorrer que as editoras devem permitir a reprodução de obras em Braille, sem qualquer remuneração, e finalidade lucrativa, dando acesso à informação. Vale ainda expor o que diz a Lei 11.126, de 27 de junho de 2005, ao determinar sobre o direito do portador de deficiência visual de ingressar e permanecer em ambientes de uso coletivo acompanhado de cão-guia; o que é mais um impulso no que se refere à locomoção do deficiente.

Após discutir sobre essa conjuntura, torna-se pertinente expor o Sistema Braille e sua contribuição para o acesso a informação da pessoa com deficiência, debatendo sobre a inclusão da tecnologia em tal segmento para que o deficiente possa fazer uso da cidadania.

\subsection{O SISTEMA BRAILLE E AS NOVAS TECNOLOGIAS}

Antigamente, os portadores de deficiência visual não tinham métodos nos quais pudessem ler e escrever. Com o passar dos anos, a sociedade começou a perceber que esses “portadores” não deveriam ser “esquecidos”. Surge então, em 1784, na cidade de Paris, a primeira escola para cegos do mundo: Instituto Real dos Jovens Cegos.

Nesse mesmo período, um jovem estudante chamado Louis Braille toma conhecimento de um método denominado Sonografia ou Código Militar, elaborado por Charles Barbil, no qual de acordo com Brasil (2001, p. 33) tinha como objetivo "possibilitar a comunicação noturna entre oficiais nas campanhas de guerra”. Esse sistema era baseado em 12 sinais, compreendido "linhas e pontos salientes”, no qual representava as sílabas da língua francesa. Esse invento foi à base para a criação do Sistema Braille em 1825, criado por Louis Braille.

O Braille, segundo Brasil (2001, p. 33), é formado da seguinte forma “consta no arranjo de seis pontos em relevo, dispostos em duas colunas de três pontos, configurando um retângulo de seis milímetros de altura por dois milímetros de largura. Os seis pontos formam o que convencionou-se chamar cela braille”.

(c) Revista Digital de Biblioteconomia e Ciência da Informação,Campinas, v.5, n. 2, p. 67-86, jan/jun. 2008- ISSN: 1678-765X. 


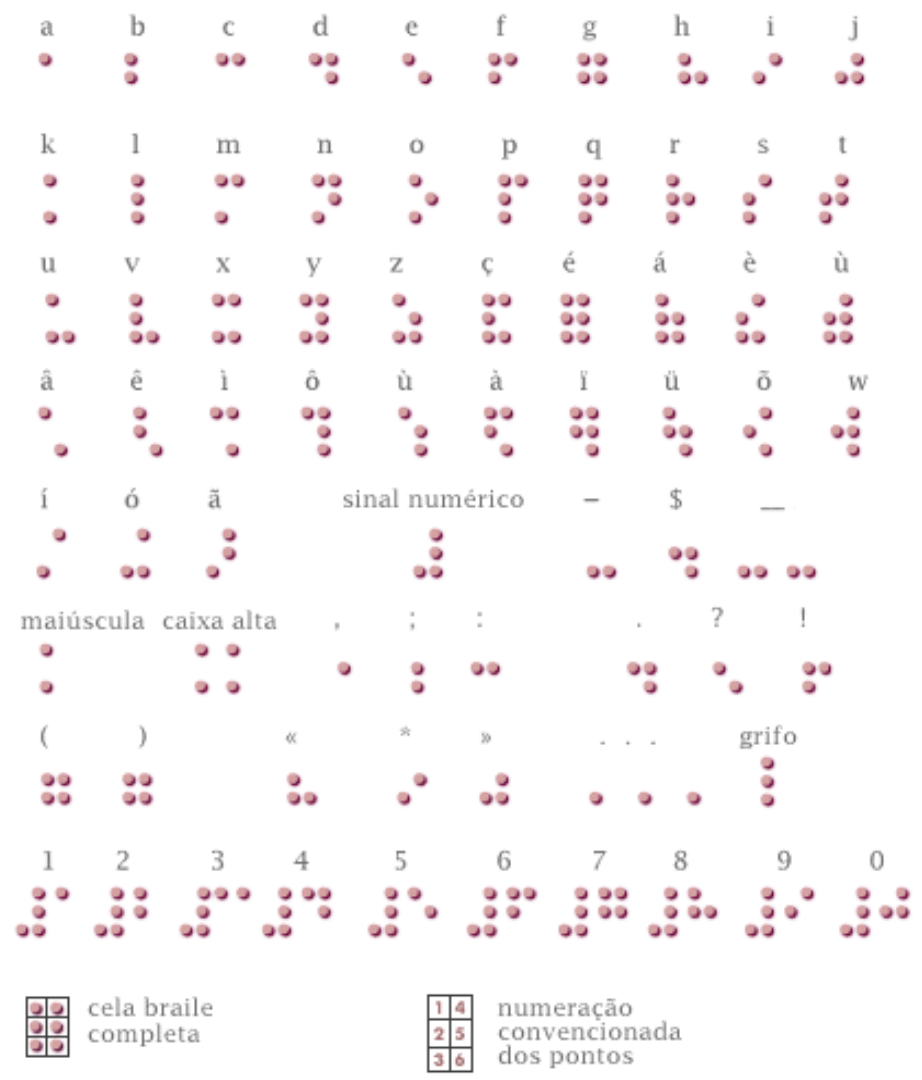

Fonte: IERC/RN

Figura 1: Alfabeto Braille

No Brasil, o braille foi adotado em 1854, pelo "Imperial Instituto dos Meninos Cegos (atualmente, Instituto Benjamin Constant)”, tornando-se a primeira instituição da América Latina a possuí-lo. Assim, os deficientes visuais começaram a poder ler, assim como também escrever, deixando o seu desengano de que nunca mais poderiam estudar novamente.

O braille é produzido através de regletes (é uma espécie de lápis para o cego, sem ele não é possível escrever em braille), os quais é constituído em duas placas de metal ou de plástico, sendo esses de mesa ou de bolso. Porém, com o advento da tecnologia outros mecanismos estão sendo utilizados para a fabricação do braille, como o uso de softwares de computadores e impressoras modernas.

Poder-se citar como exemplos desses modernos softwares, os seguintes:

- Cantal-Letras: sistema de multimídia de apoio ao processo de leitura e escrita. Através de uma interface auditiva, impressão braille e características 
interativas. Tem por objetivo facilitar a aprendizagem da leitura e da escrita dos cegos. (RODRIGUES, 2005).

- Programa Tactile Graphies Designer (TGD): é um software pedagógico criado para a geração de figuras e/ou gráficos em braille. Permite a conversão de imagens dos mais variados formatos para o sistema braille. (RODRIGUES, 2005).

Outros softwares podem ser também utilizados nas unidades de informações. Dessa forma, então, faz de uma maneira mais ágil e eficaz a interação entre deficiente visual e as informações. No caso dos computadores, esses usuários podem utilizá-lo de uma forma mais independente, ou seja, não é mais necessário que uma pessoa fique ao seu lado para lhe guiar a todo o momento. Como também, a sua própria consulta ao acervo, pode ser feita de uma maneira individual. De acordo com Rodrigues (2005), esses softwares são os seguintes:

- Dosvox: permite as pessoas com deficiência visual usar o computador de uma forma individual no estudo e no trabalho. Esse sistema interage com o usuário através de voz sintetizada, em português.

- Bibliovox: é um sistema de controle de cadastro e consulta bibliográfica vocal. Serve como ferramenta de apoio e estímulo ao processo de consulta bibliográfica e da administração do sistema.

Nota-se que através desses novos métodos criados pela tecnologia, os deficientes visuais estão conseguindo ter, hoje, um acesso mais diversificado das informações. No entanto, cabe a cada unidade de informação adaptar-se a esses recursos tecnológicos. Dessa forma, atender de uma maneira mais eficaz e ágil os seus usuários. Atualmente, algumas bibliotecas vêm tentando adaptarem-se constantemente. A utilização desses novos recursos, desde a aquisição de acervos em braille, livros falados (livros gravados em fitas cassete e CDs), como também o livro falado (permite que sejam lidos em casa livros expostos na sala 'teleg' - comunicação digital - das grandes bibliotecas, pedindo-se com antecedência as páginas desejadas), até o uso desses programas de computadores. 
Devemos perceber que as bibliotecas possuem o papel de disseminadoras da informação. Portanto, devem atender o público em geral, seja ele deficiente ou não, construindo dessa forma o valor étnico e moral de cada cidadão.

\section{INSTITUTO DE EDUCAÇÃO E REABILITAÇÃO DOS CEGOS DO RIO GRANDE DO NORTE}

O Instituto de Educação e Reabilitação de Cegos do Rio Grande do Norte, está situado à rua Fonseca e Silva, 1113, no bairro do Alecrim, Natal, foi fundado em 16 de julho de 1952 por Dr. Ricardo César Paes Barreto. É conhecido pela sigla IERC-RN. Apresenta uma área total de $2.046 \mathrm{~m}^{2}$, sendo $961 \mathrm{~m}^{2}$ de área construída. Trata-se de uma sociedade civil de direito privado, sem fins lucrativos, reconhecida como de utilidade pública municipal e estadual com registro no Conselho Nacional de Assistência Social.

A estrutura física tem capacidade para atender 200 alunos. Dispõe no momento de: auditório; refeitório; cozinha; sala de oficina pedagógica; salas de estimulação essencial; sala de computação; sala de música; biblioteca; sala de psicologia; sala de serviço social; sala de espera; sala de supervisão; sala da diretoria; secretaria; salas de aula; quadra de esporte; área de lazer com piscina e parque infantil; banheiros; sala dos professores; área de serviço; almoxarifado; sala de dança; sala de apoio a itinerância (serviços de orientação e supervisão pedagógica ao deficiente); e lojinha de artesanato.

A finalidade principal da entidade é promover a habilitação, a reabilitação e a educação das pessoas cegas ou com deficiências visuais graves, proporcionando oportunidades para o seu pleno desenvolvimento, bem como sua integração ou reintegração à sociedade, permitindo maior independência e autonomia.

Sua administração é formada pela assembléia geral, diretoria e conselho fiscal cujos membros são eleitos quadrienalmente dentre o quadro de associados da entidade. Atualmente, o seu Presidente é o Sr. Marcos Antonio da Silva.

A instituição é mantida através de convênios com o Governo do Estado e Prefeitura Municipal. No que diz respeito à seção de pessoal e recebe esporadicamente cooperação

(c) Revista Digital de Biblioteconomia e Ciência da Informação,Campinas, v.5, n. 2, p. 67-86, jan/jun. 2008- ISSN: 1678-765X. 
financeira do Governo Federal atendendo aos projetos encaminhados. As demais contribuições são oriundas dos associados da comunidade.

No contexto profissional, conta com professor de música, de braille e sorobã ${ }^{2}$ e informática, além de psicólogo, assistente social e professores para atender disciplinas como artes e pintura.. Todos esses educadores visam atender a educação especial, a estimulação essencial e a reabilitação dos deficientes visuais.

Durante a visita, ao questionar sobre a Biblioteca do Instituto, foco do estudo ora apresentado, verificou-se que ela funciona de $2^{\mathrm{a}}$ a $6^{\mathrm{a}}$ feira; os alunos têm acesso a uma biblioteca totalmente em Braille, com livros de literatura brasileira, livros didáticos, literatura infanto-juvenil e, também, a utilização da internet e de recursos didáticos, dentre os quais destacam-se: a máquina Perkins braille ${ }^{3}$, o programa Dosvox e virtual vision $^{4}$ e as impressoras braille (com os programas Duxbury ${ }^{5}$, Braille fácil ${ }^{6}$ e braivox ${ }^{7}$ ). Assim, percebe-se que o Instituto vem trabalhando as formas de inclusão a tecnologia, sendo considerado um exemplo de inclusão cidadã.

\footnotetext{
${ }^{2}$ Foi introduzido em 1908, pelos imigrantes japoneses, que o consideravam indispensável na resolução de cálculos matemáticos. Constitui-se de um conjunto de contas móveis, formando agrupamentos por classes e ordens. É um material de apoio pedagógico, de forma retangular, contendo 21 eixos, divididos em duas partes, no sentido longitudinal, por uma régua, na qual há seis pontos em relevo, separando-o em sete classes, cada uma com três ordens. Em cada eixo, há cinco contas. Na parte superior e mais estreita, há uma que, quando se junta à régua, possui valor cinco; na parte inferior, a mais larga do eixo, há quatro contas que, quando colocadas juntas à régua, apresentam o valor da ordem correspondente, ou seja, se estiverem no eixo ou ordem das unidades simples, cada conta representa o valor um.

${ }^{3}$ É um equipamento semelhante a uma máquina de escrever, utilizada para produção de textos em braille.

${ }^{4}$ Permite que os deficientes visuais façam publicações, leituras de textos inseridos no computador, e navegar na Internet.

${ }^{5}$ Com o tradutor braille pode-se criar textos -livros, documentos, cartas e outros - sem preocupar-se com regras complexas de formatação braille. Para isto é possível utilizar a maioria das impressoras braille. O tradutor é compatível com sintetizadores de voz e displays braille. Também é possível criar textos em tinta e braille na mesma página, perfeitamente alinhados.

${ }^{6}$ Pode-se editar textos através da notação Braille. O texto pode ser digitado diretamente no Braille Fácil ou importado a partir de um editor de textos convencional. O editor de textos utiliza os mesmos comandos do Bloco de Notas do Windows, com algumas facilidades adicionais.

${ }^{7}$ criada como ferramenta de impressão Braille do DOSVOX.
}

(c) Revista Digital de Biblioteconomia e Ciência da Informação,Campinas, v.5, n. 2, p. 67-86, jan/jun. 2008- ISSN: 1678-765X. 


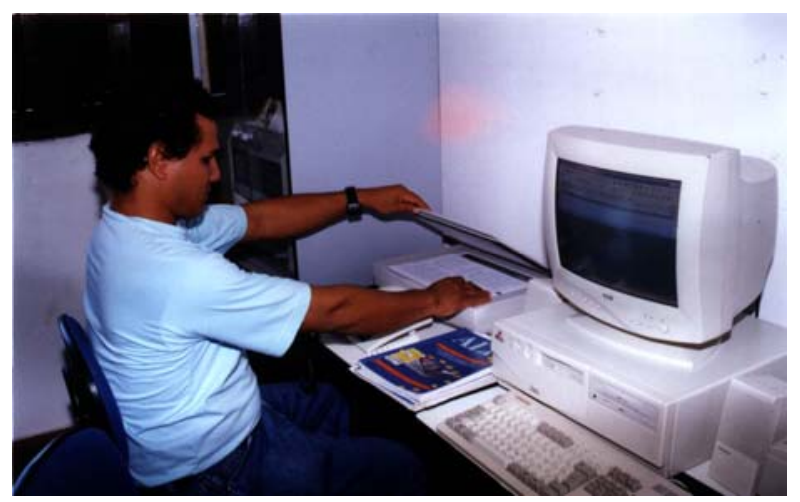

Fonte: IERC/RN

Figura 2: Utilizando a Informática

Dentre os objetivos da Biblioteca, destacam-se: oferecer suporte bibliográfico de qualidade, favorecer a integração sócio-econômica e cultural da região, dar apoio às atividades de ensino, difundindo a informação, contribuindo para a melhoria dos indivíduos que a procura.

Quanto à equipe que a compõe, constatou-se que a mesma tem certa ausência neste segmento, uma vez que não comporta nenhum bibliotecário, sendo trabalhada por uma professora formada em pedagogia. Contudo, ela possui alguns cursos de capacitação para o Braille, que faz com que haja uma melhor integração da Biblioteca.

Na conjuntura arquitetônica da instituição, verificou-se que encontra-se adequada ao seu alunado, possibilitando sua locomoção com maior segurança, o que lhe causa uma independência e auto-estima.

Verifica-se que a instituição possui objetivos claros de promover a difusão do conhecimento através do ensino, atuando muito fortemente na qualificação dos seus alunos para a formação de cidadãos melhores para o Estado e para o país.

\section{O PAPEL DO PROFISSIONAL DA INFORMAÇÃO NA INCLUSÃO DO DEFICIENTE VISUAL}

O profissional da informação é aquele que manipula, trata, dissemina, articula, domina a tecnologia e os serviços informacionais, dentre outras atribuições. A realidade é que o novo setor pede profissionais com características e habilidades específicas e não 
encontradas plenamente desenvolvidas nas profissões já existentes, ou seja, o profissional deve adequar-se ao meio que está inserido, ajustando-se a sua demanda, de modo a atendê-los com satisfação. Assim, para Bohn (1998, p. 1) "profissional é aquele que desenvolve um componente intelectual significativo de conhecimentos (saberes) e de competências (saber fazer), que o colocam na situação de prestar um serviço relevante à sociedade”.

O mercado de trabalho para o profissional da informação reage às necessidades da demanda social e é sensível à utilização de novas tecnologias. Os novos meios de transmissão da informação e da comunicação fazem com que haja contrastes entre as diferentes unidades de informação e as desigualdades nas condições e exigências do trabalho. Assim, exerce influencia no mercado de trabalho.

Para que o profissional da informação possa atuar no mercado de trabalho, primeiramente, precisa-se perceber a realidade que se está vivenciando, para que possa entender o ambiente em que atua, procurando criar mecanismos eficientes de atuação e, assim, enfrentar as mudanças que ocorrem na sociedade.

Além disso, ele deve procurar um aprimoramento contínuo. Deve adequar-se às mudanças, procurando associar os seguintes pontos: saber separar a situação real da situação ideal (realidade); entender qual é a nossa estratégia profissional (identidade); analisar o que queremos ser para a sociedade (foco); diagnosticar a nossa matéria-prima de trabalho, os nossos serviços, e produtos (processo); identificar quais as tecnologias atuais e quais as tendências das tecnologias de informação (recursos); e verificar quais as competências e habilidades necessárias ao profissional, o objeto de trabalho (perspectivas). (VALENTIM, 2002).

Vale ressaltar que, conforme o pensamento de Ohira, Prado e Schmidt (2004), o profissional da informação deve possuir as seguintes aptidões para o atendimento: orientação aos usuários; treinamentos para não usarem não somente as bibliotecas; capacitar o usuário a buscar a informação; agregar valor à informação prestada; motivação; capacidade para orientar o diálogo com o cliente; sensibilidade às necessidades dos usuários; priorizar as informações relevantes; e personalizar a forma de apresentação da informação. 
Dessa forma, entende-se que é necessário que esse profissional esteja em formação contínua, procurando atualizar-se através de cursos relacionados às tecnologias, com novos canais de distribuição, a qual é sua ferramenta básica de trabalho. Assim, é necessário que ele seja criativo, investigativo, de senso crítico, empreendedor, pro-ativo, dinâmico, político, entre outras.

Analisar o papel do profissional da informação - bibliotecário - em Unidades de Informação, para contribuir com a inclusão da pessoa com deficiência visual envolve o contexto social e a cultura da sociedade; uma vez que o espaço da biblioteca volta-se para atender os anseios e os interesses da população, isto é, procura contribuir para solução de problemas sociais. Contudo, para isso se faz necessário conhecer o seu usuário e promover o livre acesso aos registros do conhecimento.

Nesse contexto, o bibliotecário tem um papel importante, pois é dele que depende a inclusão ou a exclusão dos indivíduos com deficiências especiais. Sendo assim, ele é um dos responsáveis em adequar a unidade de informação. (PINHEIRO, 2006).

No entanto, o Estado também deve desempenhar o seu papel enquanto articulador das medidas de proteção social para as pessoas com deficiência. Para tanto, tal discussão envolve o papel do Estado no desenvolvimento das políticas públicas e o surgimento das leis que asseguram os direitos e deveres da categoria. O conjunto dessas transformações culmina no surgimento do Terceiro Setor e, consequentemente, suas Organizações Não Governamentais (ONGs). Ainda cabe chamar a atenção, mesmo que em apenas em uma sentença, para o papel positivo que as ONGs podem exercer, além de atitudes pró-ativas de toda a sociedade.

Segundo Menou e Mchombu (2004), “as comunidades desfavorecidas sofre de uma desvantagem quanto ao acesso à informação, principalmente, na utilização das Tecnologias de Informação e Comunicação (TICs)”. Todavia, o papel do bibliotecário não é lidar com as tecnologias primordialmente, nem tampouco com o livro em si unicamente, mas sim com as pessoas e os seus anseios (conteúdo / informação), pois elas são mais importantes que a informatização. Assim, entende-se que "são as pessoas que usam os livros”. (MENOU; MCHOMBU, 2004, p. 144). 
Nesse olhar social, o bibliotecário intervém em busca da democratização, para que o direito do cidadão em participar dos acontecimentos seja significativo. Visto que a biblioteca busca assegurar o acesso de todo cidadão a todos os tipos de informação e leitura, tornando-se um exercício de cidadania. Mas para o enriquecimento cultural e intelectual, permite que tenha uma visão bilateal, influenciando em suas tomadas de decisões nos aspectos políticos, econômicos, culturais, sociais e/ou educacionais.

Diante disso, Barros (2005, p. 78) enfatiza que “a biblioteca é o que o bibliotecário é”, cabendo a ele somente dar cumprimento do "fazer algo" para "mudar algo". Se esse profissional caracterizar-se como passivo e desmotivado, a biblioteca estará entregue a "inércia”; quando for criativo, transformador e ativo, a biblioteca realizará ações desenvolvidas em conjunto com a comunidade. Com isso, não basta ao bibliotecário apenas desempenhar com satisfação suas habilidade técnicas. Ele precisa habilitar-se como um agente social, possuir visões humanistas, ligadas à cultura e às artes.

Assim, o compromisso do profissional da informação, no que concerne ao deficiente visual, não está apenas na questão da acessibilidade, mas na responsabilidade social, para que lhe possa oferecer suporte às suas atividades. Para isso, é necessário criar um ambiente em que todos possam participar na busca do conhecimento. A equipe deve estar comprometida a servir o usuário deficiente, mediando o processo de democratização do acesso à informação.

\section{CONSIDERAÇÕES FINAIS}

A partir deste estudo criteriosamente elaborado, focalizou-se o deficiente visual e examinou-se que tem sido um esforço muito grande para conseguir métodos através dos quais pudessem ler e escrever de uma forma mais individualizada.

Pôde-se perceber que a visão da qual se tinha sobre a deficiência mudou muito ao longo dos anos. Os deficientes conseguiram, através de muitos esforços, os seus reais direitos reconhecidos. Todavia, ainda continuam na busca de fato da sua inclusão da maneira mais adequada à sociedade.

(c) Revista Digital de Biblioteconomia e Ciência da Informação,Campinas, v.5, n. 2, p. 67-86, jan/jun. 2008- ISSN: 1678-765X. 
Notou-se também que as dificuldades de locomoção encontradas por eles, relativas ao acesso à informação é uma questão premente. Cabe, assim, a cada unidade de informação adequar-se de uma maneira mais eficaz.

Ao abordar o Instituto de Educação e Reabilitação dos Cegos do RN, baseado em evidências, procurou-se explicar a sua importância para os deficientes visuais do Estado, pois esse foi um dos pontos observados durante as visitas de campo.

Através das análises, firmou-se definitivamente o grande valor do papel desempenhado pelo profissional da informação nessa organização. Tal relevância é salientada pelo fato de ser através do bibliotecário como mediador que ocorre o processo de disseminação e articulação das informações.

Assim, o trabalho tornou-se extremamente proveitoso, pois mostrou-nos que os bibliotecários devem estar atentos para a real necessidade desses usuários, ter em mente uma perspectiva sistêmica da qualidade de serviços, assim como o grande mérito do envolvimento e comprometimento da sociedade como um todo. Fez-nos refletir sobre o nosso futuro papel profissional na sociedade globalizada e, em particular, no nosso Estado.

\section{REFERÊNCIAS}

BARROS, Flávia Roberta dos Santos de. Bibliotecário e o compromisso social: quais as possibilidades para a realização desse encontro? In: O profissional da informação em tempo de mudanças. São Paulo: Alínea, 2005.

BEYER, Hugo Otto. Inclusão e Avaliação na Escola. Porto Alegre: Mediação, 2005.

BOHN, Maria Del Carmen R. O ensino na área de controle sobre a perspectiva da competência: experiência no curso de Biblioteconomia da UFSC. Disponível em: <http://www.encontros-bibli.ufsc.br>. Acesso: 4 out. 2006. 
BRASIL. Secretaria de Educação Especial. Política nacional de educação especial. Livro 1. Brasília: SEESP, 1994. Disponível em: <http://www.defnet.org.br>. Acesso em: 21 set. 2006.

. Ministério da Educação. Secretaria de Educação Especial. Programa de capacitação de recursos humanos do ensino fundamental: deficiência visual. v. 2. Brasília: MEC/SEE, 2001.

BUSCAGLIA, Leo. Os deficientes e seus pais. 3. ed. Rio de Janeiro: Record, 1997. 415p.

ESTABEL, Lizandra Brasil; MORO, Eliane Lourdes da Silva; SANTAROSA, Lucila Maria Costi. A inclusão social e digital de pessoas com limitação visual e o uso de tecnologias de informação e de comunicação na produção de páginas para a internet. Ciência da Informação, v. 35, n. 1, Brasília, jan/abr. 2006. Disponível em: <http://wwwscielo.br>. Acesso em: 23 out. 2006.

FERNANDES, Dirce Missae Suzuki. O deficiente visual e a biblioteca central da UEL: relato de experiência. 2000. Disponível em: <http://snbu.bvs.br/snbu2000>. Acesso em: 21 set. 2006.

FERREIRA, A.B.H. Novo Dicionário da Língua Portuguesa. 2. ed. Rio de Janeiro: Nova Fronteira, 1986.

GIL, Antonio Carlos. Como elaborar projetos de pesquisa. 4. ed. São Paulo: Atlas, 2002.

MASINI, Elcie. O Perceber e o Relacionar-se do Deficiente Visual. Brasília, Coordenadoria Nacional Para Integração da Pessoa Portadora de Deficiência - CORDE, 1994. 
MENOU, Michel J.; MCHOMBU, Kingo. Os profissionais da informação em comunidades desfavorecidas. In: Atuação profissional na área de informação. São Paulo: Polis, 2004.

OHIRA, Maria Lourdes Blatt; PRADO, Noemia Schoffen; SCHMIDT, Luciana. Profissional da informação no limiar do século XXI: enfoque nos periódicos brasileiros em biblioteconomia e ciência da informação (1995/2002). Revista Eletr. Biblioteconomia e Ciência da Informação, Florianópolis, n. 17, 2004.

PINHEIRO, Danielle da Silva. O bibliotecário e o atendimento aos usuários com necessidades especiais em unidades de informação. Revista de Iniciação Científica da FFC, Marília, v. 4, n. 3, 2004. Disponível em: <http//www.revistas.marilia.unesp.br>. Acesso em: 23 out. 2006.

RODRIGUES, Graziela Cristina do Vale Pascoal. Vídere: jogos para estimulação visual. Trabalho de Diplomação apresentado ao curso de Tecnologia em Informática. Cornélio Procópio/PR, abril de 2005. Disponível em: <http://www.cfet.pr.br>. Acesso em: 3 nov. 2006.

VALENTIM, Marta Lígia Pomim. Formação: competências e habilidade do profissional da informação. In: Formação do profissional da informação. São Paulo: Polis, 2002. 


\section{Alessandra Patrícia de Araújo}

Aluna do $4^{0}$ período do Curso de Biblioteconomia da Universidade Federal do Rio Grande do Norte (UFRN). astuciosabiblio@yahoo.com.br

\section{Edineide da Silva Marques}

Aluna do $4^{0}$ período do Curso de Biblioteconomia da Universidade Federal do Rio Grande do Norte (UFRN).

\section{Maria Luzia Alexandre de Oliveira}

Aluna do $4^{0}$ período do Curso de Biblioteconomia da Universidade Federal do Rio Grande do Norte (UFRN).

\section{Eliane Ferreira da Silva}

Orientadora: Prof. Dra . Cátedra do Curso de Biblioteconomia da Universidade Federal do Rio Grande do Norte (UFRN).

Recebido em: 25/02/07

Aceito para publicação em: jun. 2007 